\title{
THE CHANGING CONTEXTS OF FAMILY CARE IN CANADA
}

\author{
Carolyn J. Rosenthal
}

IESOP Research Paper No. 10

January 1997

The Program for Research on the Independence and Economic Security of the Older Population is an interdisciplinary research program established at McMaster University with support from Health Canada’s Seniors’ Independence Research Program. The Research Paper series provides a vehicle for distributing the results of studies undertaken by those associated with the program. Authors take full responsibility for all expressions of opinion.

For further information about the research program and other papers in this series, see our web site at: http://socserv2.mcmaster.ca/ iesop/

Note: This paper is cross-listed as No. 324 in the McMaster University QSEP Research Report Series. 


\title{
THE CHANGING CONTEXTS OF FAMILY CARE IN CANADA
}

\author{
by \\ Carolyn J. Rosenthal, Ph.D. \\ Office of Gerontological Studies \\ McMaster University \\ Hamilton, Ontario, Canada
}

Forthcoming, Ageing International. Revised version of a paper presented at the Colloquium, "The Aging Process Revisited," University of Montreal, Montreal, Quebec, October, 1996. Address correspondence to: Carolyn J. Rosenthal, Director, Office of Gerontological Studies, McMcaster University DC 229, Hamilton, Ontario, Canada L8S 4K1. 
ABSTRACT

\title{
THE CHANGING CONTEXTS OF FAMILY CARE IN CANADA
}

\author{
Carolyn J. Rosenthal \\ McMaster University
}

Over the past 20 to 30 years, the importance of families as providers of assistance to older Canadians has been well documented through research. However, over these decades, the contexts within which families exist and provide support have changed considerably. This paper examines changes over this time period which affect family support to older adults. Specific areas examined include: likelihood of having a parent alive; living arrangements; divorce and single-parenthood; women's labour force participation, and combining employment and care of older relatives. The paper concludes with an assessment of policy changes in health and long-term care as these affect older Canadians and their families. 


\section{THE CHANGING CONTEXTS OF FAMILY CARE IN CANADA}

\section{INTRODUCTION}

The importance of families as providers of assistance to older Canadians has been well documented through research (Rosenthal, 1987; Connidis, 1989). When older people require help, they typically turn to family members, especially spouses and children. Women -- wives and daughters -- are the most common helpers. In the 1950s, popular and scholarly emphases on the nuclear family unit led to the myth that older people had been abandoned by their children. However, research in the ensuing decades has demonstrated the emotional and functional bonds between kin, suggesting that families continue to be important sources of support to all generations, including the oldest. At the same time, contemporary families are not identical to families in the past. The contexts within which families exist have changed considerably, thus changing the context for family help to older people.

Support to older people takes place in a variety of contexts -historical, political and economic. These contexts vary across nations and they also vary over time. In general, gerontological research on family support has paid little attention to the ways in which changing contexts have affected patterns of family care. One exception, perhaps, is that the increase in labour force participation by women, who are traditionally the ones to provide care to older relatives, has prompted researchers to examine the 
relationship between paid employment and care provision (see below) .

In Canada, over the past two to three decades, a number of developments have begun to affect the provision of family care. The purpose of this paper is to examine these changes and their impact on family support to older Canadians. The paper concludes with an assessment of changes on social policy for older Canadians.

\section{THE CHANGING FAMILY CONTEXT}

Increasing likelihood of having a parent alive:

At the level of the family, population aging has resulted in a significant increase in the likelihood that a middle-aged adult will have an surviving parent. Gee (1990) has compared the proportion of three Canadian birth cohorts having a surviving parent at age 50 and 60. Among Canadians born in 1910, only 33\% of individuals at age 50 had a surviving parent. This rose to $49 \%$ of those born in 1930, and is expected to rise to 60\% of those born in 1960. The likelihood of having a surviving parent at age 60 has increased from 8\% of those born in 1910 to 16\% for those born in 1930, and is predicted to rise to 23\% for those born in 1960 .

It has thus become the majority pattern to have a surviving parent at age 50 and is becoming more common to have one even at age 60. An associated phenomenon is the growing likelihood that young adults still have a grandparent alive. These changes are, first and foremost, cause for celebration. Too often, the emphasis is on the negative aspects of population aging, rather than on the 
benefits within families of this new generational overlap of lives. On the other hand, these developments have led to a growing likelihood that families will include older members who may need care. It should also be noted that after about age 40 a majority of Canadians have experienced the death of the first parent (Rosenthal, Martin-Matthews and Matthews, 1996) and therefore have a surviving widowed parent. This raises the likelihood that children will be the ones to provide help to parents, should help be needed.

\section{Living arrangements:}

The second aspect of the changing family context concerns the living arrangements of older people. Since about 1960, there has been a trend for older Canadians to live either as a married couple or alone. This trend is especially pronounced among women (Connidis, 1989:5, Wister, 1985). Between 1961 and 1991, the proportion of women aged 65+ living alone more than doubled, rising from 16\% to 34\% (Martin Matthews, 1991: 79). Among widowed women, the proportion living alone is close to 80\% (Martin Matthews, 1991: 79) .

The trend to independent living has implications for family care in that, should an older parent need care, separate residence makes care provision more complicated. As the need for care intensifies, adult children may have a parent move in with them. Only limited data are available on this issue. One study suggests that establishing co-residence as a strategy to accommodate caregiving 
responsibilities is very uncommon in Canada. In that study, which examined the experiences of 250 Canadians who were providing a significant amount of assistance to older relatives, only 3\% to 7\% of care recipients moved in with a caregiver over a two-year period (CARNET, no date).

Divorce and single-parenthood:

A third feature of the changing family context concerns divorce. Canada experienced a sharp rise in divorce rates after laws were liberalized in 1968. Family structure has become more complex. Through marriage to someone who has been married before, individuals acquire "step-children," that is, children of their spouse through his/her former marriage. When middle-aged adults divorce, their older parents acquire "former children-in-law." Divorce and remarriage may create extra sets of grandparents for children. The relationship between this change and family care of the elderly has yet to be carefully examined by research, but one might hypothesize at least some negative effects, and possibly some positive effects, for example a larger network of potential support. One negative effect is seen at the level of public discourse where old people and single parent families are portrayed as competing for public dollars, with the elderly pictured as receiving more than their share of public benefits.

Combining work and family:

Women's labour force participation: 
A trend with great importance for family care is the dramatic increase in labour force participation among women; this has grown from 30\% in 1961 to 60\% in 1991 and is predicted to reach 66\% by the end of the century (Report of the Committee on Women and Economic Restructuring, 1994:5; McDonald, 1996:7). Especially noteworthy are the increases in labour force participation among married women and women with children at home, meaning that combining work and family roles has become much more common. Well over half of married women are in the paid labour force (Beaujot, 1995). By 1989, dual-earner families made up 62\% of all husbandwife families, compared with 32\% in 1967 (Statistics Canada, 1991). Over 60\% of mothers with children at home now work in the paid labour force. Between 1976 and 1984, the proportion of women with children under the age of three who were in the paid labour force rose from 32\% to 52\% (Connolly and MacDonald, 1990).

\section{The changing nature of work:}

The nature of work itself has been changing. A major trend is the increase in "non-standard" work (McDonald and Chen, 1994), that is, part-time, short-term, temporary work or self-employment. Nonstandard employment accounted for $44 \%$ of all employment growth in Canada in the last decade, and accounted for $28 \%$ of all employment in 1989 (McDonald and Chen, 1994). Women are over-represented in non-standard work because of the high proportion of women who work part-time. Over $70 \%$ of part-time workers are women (McDonald and Chen, 1994). Family care responsibilities are a major reason women 
work part-time.

\section{Employment and Eldercare:}

The increased likelihood of having a parent alive combined with the growth in women's labour force participation means that it is more common than in the past for Canadians to face the issue of balancing employment with responsibilities for the care of an older relative. Of course, some caregivers leave the labour force; about 9\% of formerly employed Canadian women aged 55-64 say they retired because of caregiving responsibilities (McDonald, 1996). Many -or, possibly, most --caregivers, however, remain in the labour force. Overall, about 12-16\% of employed Canadians are actively involved in helping older family members (Martin Matthews and Rosenthal, 1993), although estimates vary widely because the definition of care varies among studies. In a study of 5,400 employed Canadians conducted by CARNET: The Canadian Aging Research Network (Martin Matthews and Rosenthal, 1993), 46\% of respondents reported providing some assistance to an older relative in the previous six months. Twelve per cent reported helping with the demanding tasks of personal care and spent on average nine hours a week helping their older relatives -- the equivalent of an extra work day. Another interesting figure comes from The Canadian study of Health and Aging (1994) which found that 36\% of all informal primary caregivers of persons with dementia were employed.

Canada does not have a national policy on support for employed 
workers who care for elderly dependents (Martin Matthews and Rosenthal, 1993). Many employers believe that family responsibilities are the employee's problem, and that family and work life should be kept separate (Canadian Employment and Immigration Advisory Council, 1987:24; Martin Matthews and Rosenthal, 1993). Nonetheless, family responsibilities are having an increasing impact on the workplace. One Canadian report cites Statistics Canada data showing a 100\% increase from 1977 to 1987 in absenteeism for personal or family reasons, with 37\% of this increase attributed to time spent caring for an elderly relative (Ontario Women's Directorate and Ontario Ministry of Community and Social Services, 1991:18). Employers in Canada currently provide a range of leaves to deal with a variety of family situations. However, these are not available across the country and depend to a great extent on the size of the company, the nature of any collective agreement, provincial legislation, corporate profitability, and corporate culture. Many employees must use their own sick or vacation leave to cover their absences, or take unpaid leave (Martin Matthews, 1994).

\section{Multiple Roles:}

Another new and important trend among Canadian women is the simultaneous occupancy of the multiple roles of parent, child, and employed worker, creating the structural potential for conflicting demands. To establish the prevalence and distribution of various 
role combinations, my colleagues and I analysed data from the 1990 General Social Survey of Canada, from which generalizations may be made to the Canadian population (Rosenthal, Martin-Matthews and Matthews, 1996). Using a sample aged 35-64, we investigated four issues related to multiple roles. We were particularly interested in role occupancy among women, and especially those combinations which denote being in the "sandwich generation" (the currently popular term for the situation of adults who face competing demands from upper and lower generations, as well as from paid employment).

First, we asked what proportion of middle-aged women have a parent alive. We found that although the great majority aged 35-49 have a living parent, the proportion of women who have no living parents rises from 47\% among women aged 50-54, to 61\% among women aged 55-59 and to 79\% among women aged 60-64. Obviously, women who do not have a living parent cannot be "sandwiched" between responsibilities for elderly parents and other role commitments. For those over age 50 who do have a parent alive, the parent is typically over age 75, suggesting an increasing risk of functional limitation and need for assistance.

Next, we asked what proportion of middle-aged women are "sandwiched" by virtue of occupancy of multiple roles. Three combinations were of particular interest: (1) adult child and paid worker; (2) adult child and parent of a dependent child (defined as a child living in the respondent's household), and (3) adult child, paid worker, and parent of a dependent child.

A majority of women (between 55\% and 58\%) aged 35-49 combine the 
roles of adult child and paid worker. The proportions fall dramatically after this, however, from 25\% at ages 50-54, to 15\% at ages 55-59, to less than 5\% at ages 60-64. Turning to the second combination of roles, adult child and parent of a dependent child, the proportions of women who combine these two roles drops from 71\% among women aged 35-39 to 51\% among women aged 45-49 and 24\% among women aged 50-54.

The prototypical "sandwich generation" situation is represented by the third combination of roles: adult child, parent of a dependent child, and paid worker. This role configuration holds the greatest structural potential for competing demands, should an older parent need care. This combination drops from 42\% in the 4044 age group to 35\% in the later $40 \mathrm{~s}$ and to very small proportions after that. It must be noted, however, that women in these older age categories who do have a parent alive are quite likely to face care responsibilities, given the parent's advanced age.

The various roles -- adult child, employee, parent -- create the structural potential for conflict as women try to meet their various role demands. We then asked: What proportion of women who occupy the adult child role actually help their parent with one or more types of tangible help once a month or more often? We found that rather small percentages of daughters -- from 11\% to 22\%, depending on the age category -- helped this often. Only 1\% or 2\% of daughters provide personal care, with the noteworthy exception of daughters aged 50-59 among whom 6\% to 7\% provide such care. That is, although very low percentages of daughters provide personal 
care, the age 50-59 seem to be the time when this occurs. Prior to that age period, parents typically need less intensive help and after that, the type and extent of care required may be so great that parents must be institutionalized.

Finally, we asked: Among adult children who help a parent at least monthly, what proportion also occupy the roles of parent and employee and might therefore be considered to be "caught in the middle" or "sandwiched"? In all age categories, the proportions of daughters in the potentially most difficult combination of roles who actively helped parents were very small. More specifically, among women who had a living parent, a child at home, and a paid job, the highest percentage who helped a parent at least monthly was 7\%. Being truly "sandwiched" or "caught in the middle" is therefore very uncommon. Among daughters, active help to parents is more common at older ages when there are fewer potentially conflicting roles. Thus, for example, while 18\% of daughters aged 55-59 provided active help to parents, these daughters no longer had a child in the household and most were not in the paid labour force. In sum, the highest proportions of daughters who help parents are not in the configurations denoting multiple roles.

Our analysis has a number of limitations, but it does indicate that relatively small proportions of adult children provide tangible, regular help to older parents, and even smaller proportions are in a situation that fits the popular portrayal of the sandwich generation. We should, therefore, avoid very broad assertions that caregiving by middle-aged women to older parents is 
common. Similarly, we should avoid placing undue emphasis on the "sandwich generation" phenomenon (see, for example: Foot, 1996:192194). Those who do carry these multiple role responsibilities, however, often find the combination extremely difficult, and indeed caregivers face many difficulties regardless of their other roles.

Employed caregivers are somewhat at the mercy of the benefits available in their workplace, a context about which I have already spoken. The other vitally important context in which all caregivers must function is that related to health care, a context which is changing rapidly in Canada.

\section{THE CHANGING CONTEXT OF HEALTH POLICY AND LONG-TERM CARE}

In recent years, social policy in Canada (as elsewhere) has endorsed a shift from institutional to community-based care for the elderly. In the same period, Canada has experienced economic recessions and shifts to political conservatism. Cutbacks in social programs have been substantial, accompanied by pressures for further restraints. Given the ongoing increases in the very old population, one cannot help but worry that social policy, fiscal pressures and demographic realities are on something of a collision course (Rosenthal, 1994).

The policy shift advocating community-based care occurred in the 1980s and coincided with the seeking of a better-coordinated and rationalized system of long-term care (for a review of the longterm care system in Canada and issues in long-term care reform, see: Deber and Williams, 1994). This shift to community-based care 
is not, in itself, a negative direction. Historically, Canada has had a comparatively high rate of institutionalization. Moreover, remaining in the community as long as possible is what older people and their families want. Nonetheless, many concerns accompany this shift. One concern (examined in more detail below) is that it is fairly clear that governments expect families to fill the gaps in care that may arise.

In Canada, long-term care is not formally subject to the principles of the country's universal health care system, and arrangements vary from province to province. The following discussion frequently refers to the province of Ontario, but the situation is similar in other provinces. Ontario, thus, provides an ilustrative example.

The federal government provides substantial funding for health care through transfer payments to the provinces. In the mid-1990s, the federal government announced substantial cuts in these transfer payments, to be phased in over the next few years. These cuts come on the heels of difficult economic times in Ontario and most other provinces.

One aspect of the policy shift to community care -- but more accurately seen as a response to funding cuts -- has been a severe restriction on growth in the number of hospital beds. Denton and Spencer (1995) have documented this in Ontario for the period 1980 to 1990. While aging and population growth would have suggested a need for hospital bed-days that was 22\% higher in 1990 than in 1980, the number of bed-days actually declined. To date, however, 
older patients have not been affected by this decline; indeed, their length of stay actually increased (see also: Barer, Evans and Hertzman, 1995). This, however, may be small and temporary comfort. Denton and Spencer (1995) project that the demand for health care services, including acute and long-term care institutional beds will grow considerably faster than the availability of these services. These researchers note that restrictions on the availability of long-term institutional beds have been quite severe in recent years. The implications for families are obvious: if institutional care is not available, who other than families will fill that care gap?

To ascertain the role of family support in policy directions in long-term care, Rosenthal and Neysmith (1990) conducted an analysis of public documents iterating long-term care policy in the province of Ontario for the time period 1986-1990. The purpose was to identify the role of family support in long-term care policy. The general thrust of the documents was to promote a move to communitybased care, and recommendations and conclusions concerning informal support were lodged within this broader context. Five major themes were identified in the analysis.

The first theme was that family care is the ideal model of care. The goal of services such as home support is to sustain and expand the family's capacity to provide care (Ontario Ministry of Community and Social Services, 1989). The role of services is to support family care, not replace it. For example, one document stated: 
"...the goal of home care programs across the country is...to increase the capacity of families and other social networks to provide care for persons in need" (Health and Welfare Canada, $1985)$.

The second theme was that community care is recommended first and foremost because it is perceived as cost-saving. Family caregiving is to be supported because this will help save public money. For example,

"There are some obvious economies if older people are able to continue living in the community...they may have family members, neighbours and friends, who can perform essential tasks for them...the heavy reliance by older persons on the health care system as we know it today suggests there is good reason to look for alternative arrangements, which may be cheaper and as effective" (Health and Welfare Canada, 1986). These words are ominous indeed to those who are concerned that the shift to community care might overburden the families, and especially overburdening women who to whom caring tasks so typically fall.

The third theme was that the policy recommendation regarding provision of community services seems to be a "residual policy"; that is, services will be provided where family members are not available or where family cannot provide the necessary service.

The fourth theme was that recommendations to support family caregivers equate support with instrumental support, that is, the performance of tasks. The goal of supporting family caregiving is 
thus to enable the family to continue to perform tasks. Only rarely is it recognized that support has different dimensions. For example, these documents totally neglect emotional support, an aspect of support which is of great importance to most older people, and an aspect of support which might suffer when the balance of care shifts to instrumental support (Rosenthal, 1994).

The fifth theme was that assessments will be pivotal in a system of community-based care. A single entry point is recommended -- to be accomplished through establishing a number of single access centres which would combine information, referral, service coordination and service provision on a case-managed basis. Service prescription will flow from assessment. While explicit discussion focuses on functional assessment as a basis for prescribing services, implicit in the discussion is that family availability will be an important criterion. Services may well have fees attached, and community care may involve increased expenditure for family caregivers and care recipients.

It is noteworthy that both respite care and day care programs typically require a fee. One document justifies this as follows: "This practice is intended to acknowledge the responsibility of any individual or family in providing care as well as to give caregivers a greater sense of ownership in the service they receive. Because they contribute to the cost of care, caregivers may feel more comfortable about making suggestions or recommending changes in the respite services" (Ontario Ministry of Community and Social Services, 1987). One might well counter that these families 
are already contributing quite a lot to the "cost" of care. Further, this is the same argument that is made by those advocating the introduction of user fees for medical services, an argument Canadians have, to date, vehemently resisted.

It is clear from policy statements that governments expect families to provide more care than ever to frail elderly who, increasingly, will remain in the community (where many associated with the aging field worry that, in an era of funding cuts, services and programs will increasingly be under-funded or absent) . It is well established that the bulk of caregiving in families is done by women. Despite the strong trend toward female labour force participation, government policy seems to be based on the assumption that women will be available to provide informal care when formal sources become more scarce or unavailable. Such an assumption is clearly dangerous for everyone. Older people may be left without adequate sources of support. Or, women may leave paid employment, thereby damaging their own present and future economic situations (McDonald, 1996).

One of the worries about community-based care is cost -- who pays? In Canada, long-term institutional care has not, to date, been a heavy financial burden for individuals or families. Community care is likely to entail a number of new financial costs for families, for example, the purchase of additional formal support services. One might well speculate that the cost of maintaining a disabled older person in his or her own residence in the community would be greater than the cost of maintaining that 
person in a long-term care facility such as a nursing home. The most likely scenario seems to be that much of that additional cost will be "offloaded" onto families and thus "invisible". This shifting of costs from government to families seems almost inevitable as the shift from institutional to community care is implemented. As Susan McDaniel asks, "How is it that caring within the family is seen as costless to individuals and to society, whereas caring by society is defined as costly?" (McDaniel, 1994:139).

Governments have always maintained that the policy shift from institutional to community care would be accompanied by adequate increases in funding to the community sector. Havens (1995) has discussed the need for funding to move, as actual budget dollars, from lowered priority programs to those with raised priority. She argues that while policy rhetoric across canada is paying lip service to these budgetary moves, to date very few actual dollars have moved to alternate programs (Vowles, 1994). Savings that have been realized either have remained within the same sector or have disappeared from the health care sector altogether, being directed instead toward deficit reduction. The critical shift involves moving dollars and services from the acute care and medical systems to the chronic and rehabilitative care facilities, to the nursing homes, the community long-term care or home care programs, and community service programs. Unless we are successful in moving funds across sectors, Havens says we face either very high user fees or informal caregivers will be left to provide care on their 
own, unsupported by formal services. (Havens, 1995; see also, Rosenthal, 1994).

The hospital sector has experienced severe budget cuts, but funding to the community has not increased proportionately. Although community budgets have increased, the real issue is whether funding has increased sufficiently to keep pace with the greater numbers of older people and the increase in frailty and disability. The example of home care, a vital component of community care, provides an interesting example of what is happening in the community sector in Ontario. Home care used to be an insured service; if a person was deemed eligible, he/she was entitled to home care. Two years ago, the government, in an effort to slow or manage the growth of home care, capped this service. While the amount available may have increased from previous years, it was given to regions in the form of a fixed amount. To illustrate the potential for discrepancy between the amount of funding and the growing need, in one region of Ontario the number of people receiving home care has tripled in the past 6 years (Muggah, 1996). Is the amount of home care sufficient to meet this growing need? Although there are only anecdotal data, practitioners report that there is "less service to go around" than in the past (Muggah, 1996). Under these conditions, services must go to those with the highest level of need, not always the best strategy if one is interested in maintenance or prevention, and not always a strategy that helps caregivers. 


\section{CONCLUSION}

Perhaps the fundamental question, one which is rarely explicitly asked, is: Who should have responsibility for the care of the elderly? Should families be the primary providers of care? More precisely, should wives and daughters (and perhaps daughters-inlaw) be the primary providers of care? Chappell notes that family care has become a cornerstone in the rhetoric of reform for health care in Canada -- as we have seen demonstrated in the province of Ontario. Chappell goes even further and states that Canada is witnessing the emergence of "a new paradigm for health care in which it is believed that government efforts to improve the quality of life of individuals and families can be harmful [and] that the family should not be relieved of traditional caring tasks" (1994).

Scholars have long argued that the distinction between the private world of the family and the public world of the economy is artificial (Neysmith, 1991:277; Ungerson, 1990). What we are currently witnessing in Canada, with the shift to community care and greater reliance on family caregiving, is a reinforcing of this ideology, in which family responsibilities are viewed as private troubles rather than public issues (Mills, 1963).

Canada needs policy initiatives that mesh with the current realities of families, not with myths or idealizations. The ideological division between the private world of the family and the public world of the economy needs to be recognized as artificial. This would help shift the policy focus to, for example, the growing support needs of employed workers with elderly 
dependents (Canada Employment and Immigration Advisory Council, 1987:vii) and the negative economic consequences for women (or men) who leave paid employment to provide care to older relatives. More broadly, it must be recognized that the needs of contemporary families are different from those of families in the past and that new policy solutions must be derived to meet these changing realities. 


\section{References}

Barer, M.L., Evans, R.G. and Hertzman, C. 1995. "Avalanche or Glacier?: Health Care and the Demographic Rhetoric," Canadian Journal on Aging $14(2): 193-224$.

Beaujot, R. 1995. "Family Patterns at Mid-Life (Marriage, Parenting and Working)." Pp. 37-75 in R. Beaujot, E. Gee, F. Rajulton and Z. Ravanera (Eds.), Family Over the Life Course: Current Demographic Analysis. Ottawa: Statistics Canada, Demography Division.

Canada Employment and Immigration Advisory Council. 1987. Workers with Family Responsibilities in a Changing Society: Who Cares? (Publication No. WH-6-174E).

Canadian Study of Health and Aging. 1994. "Patterns of Caring for People with Dementia in Canada," Canadian Journal on Aging $13(4): 470-487$.

CARNET: The Canadian Aging Research Network. No date. Work and Eldercare Survey, unpublished data. Guelph, Ontario: University of Guelph.

Chappell, N.L. 1994. Health Care Reform: Will it be Better or Worse for Families? Plenary Address, Annual Meetings of the Canadian Association on Gerontology, Winnipeg, October 13 . 
Connidis, I. 1989. Family Ties and Aging. Toronto and Vancouver: Butterworths.

Connolly, M.P. and MacDonald, M. 1990. Women and the Labour Force. Ottawa: Statistics Canada. (Publication No. 98-125)

Deber, R. and Williams, A.P. 1995. "Policy, Payment and Participation: Long-Term Care Reform in Ontario," Canadian Journal on Aging 14(2):294-318.

Denton, F.T. and Spencer, B. G. 1995. "Demographic Change and the Cost of Publicly Funded Health Care," Canadian Journal on Aging $14(2): 174-192$.

Foot, D. K. 1996. Boom, Bust and Echo. Toronto: Macfarlane Walter and Ross.

Gee, E.M. 1990. "Demographic Change and Intergenerational Relations in Canadian Families: Findings and Social Policy Implications," Canadian Public Policy XVI(2):191-199.

Havens, B. 1995. "Long-Term Care Diversity within the Care Continuum," Canadian Journal on Aging 14(2):225-244.

Health and Welfare Canada. 1986. Aging: Shifting the Emphasis. Ottawa, Ontario: Health and Welfare Canada, Health Services and 
Promotion Branch.

Health and Welfare Canada. 1985. Profiles on Home Care/Home Support Programs. Ottawa, Ontario: Health and Welfare Canada.

Martin Matthews, A. 1991. Widowhood in Later Life. Toronto and Vancouver: Butterworths.

Martin-Matthews, A. 1994. Canadian Responses to Managing Work and Informal Care of Frail Elders: Public Policy and Private Practice. Paper presented at the annual meetings of the Gerontological Society of America, Atlanta, Georgia, November.

Martin Matthews, A. and Rosenthal, C.J. 1993. "Balancing Work and Family in an Aging Society: The Canadian Experience." Pp. 96-119 in G.L. Maddox and M.P. Lawton (Eds.), Annual Review of Gerontology and Geriatrics, Volume 13. New York: Springer.

McDaniel, S. 1993. "Caring and Sharing: Demographic Aging, Family and the state." Pp. 129-143 in J. Hendricks and C.J. Rosenthal (Eds.), The Remainder of Their Days: Domestic Policy and Older Families in the United States and Canada. New York: Garland.

McDonald, L. 1996. Transitions into Retirement: A Time for Retirement. Final Report to National Welfare Grants Program Human Resources Development Canada. Toronto, Ontario: Faculty of Social 
Work, University of Toronto.

McDonald, P.L. and M.Y.T. Chen. 1994. "The Youth Freeze and the Retirement Bulge: Older workers and the Impending Labour Shortage." Pp. 113-139 in V.W. Marshall and B. McPherson (Eds.), $\underline{\text { Aging: }}$ Canadian Perspectives. Peterborough, Ont.: Broadview Press.

Mills, C.W. 1963. Power, Politics and People: The Collected Essays of C. Wright Mills. New York: Basic Books.

Muggah, Betty (Executive Director, VON, Hamilton Wentworth Branch of the Victorian Order of Nurses, Hamilton, Ontario). 1996. Personal Communication.

Neysmith, S. 1991. "A Social Model of Care." Pp. 272-299 in C. Baines, P. Evans and S. Neysmith (Eds.), Women's Caring: Feminist Perspectives on Social Welfare. Toronto: McLelland and Stewart.

Ontario Ministry of Community and Social Services. 1989. Evaluation of the Integrated Homemaker Program, Final Report. Toronto: Ontario Ministry of Community and Social Services.

Ontario Ministry of Community and Social Services. 1987. Guidelines for Family Respite Programs. Toronto: Ontario Ministry of Community and Social Services. 
Ontario Women's Directorate and the Ontario Ministry of Community and Social Services. 1991. Work and Family: The Crucial Balance. Toronto: Author.

Report of the Committee on Women and Economic Restructuring. 1994. Women and Economic Restructuring. Ottawa: Canadian Labour Market and Productivity Centre.

Rosenthal, C.J. 1987. "Aging and Intergenerational Relations in Canada." Pp. 311-342 in V.W. Marshall (ed.), Aging in Canada: Social Perspectives, 2nd Edition. Markham, Ontario: Fitzhenry and Whiteside.

Rosenthal, C.J. 1994. "Long-Term Care Reform and 'Family' care: A Worrisome Combination" [Editorial]. Canadian Journal on Aging $13(4): 419-427$

Rosenthal, C.J. and Neysmith, S. 1990. Informal Support to Older People: Conclusions, Forecasts, Recommendations and Policy Prescriptions in Recent Policy Deliberations. Unpublished report prepared for Statistics Canada.

Rosenthal, C.J., Martin-Matthews, A. and Matthews, S.H. 1996. "Caught in the Middle? Occupancy in Multiple Roles and Help to Parents in a National Probability Sample of Canadian Adults," Journal of Gerontology: Social Sciences 51B(6):S274-S283. 
Statistics Canada. 1991. Characteristics of Dual-Earner Families 1989. Ottawa, Ontario: Statistics Canada.

Ungerson, C. 1990. "The Language of Care: Crossing the Boundaries." Pp. 8-33 in C. Ungerson (Ed.), Gender and Caring: Work and Welfare in Britain and Scandinavia. London: Harvester Wheatsheaf.

Vowles, A. 1994. "Home Remedies: Home Care Network Fills Gaps in Support Systems," Health Economics (March):19-21.

Wister, A. 1985. "Living Arrangement Choices among the Elderly," Canadian Journal on Aging 4(3):127-144. 
No. 1: $\quad$ Public Pensions in Canada

J.B. Burbidge

No. 2: How Old Is Old? Revising the Definition Based on Life Table Criteria

F.T. Denton

B.G. Spencer

No. 3: The Future Population of Canada and Its Age Distribution

F.T. Denton

C.H. Feaver

B.G. Spencer

No. 4: $\quad$ Caught in the Middle? Occupancy in Multiple Roles and Help to Parents in a National Probability Sample of Canadian Adults

No. 5: Women, Work and Caregiving: How Much Difference Does a Great Job Really Make?

C.J. Rosenthal

A. Martin-Matthews

S.H. Matthews

A. Martin-Matthews

C.J. Rosenthal

No. 6: Health and the Transition from Employment to Retirement

V.W. Marshall

P.J. Clarke

No. 7: $\quad$ Aging and Work in Canada: Firm Policies

V.W. Marshall

J.G. Marshall

No. 8: The Changing Economic Circumstances of the Older Population:

A Cohort Analysis

F.T. Denton

B.G. Spencer

No. 9: $\quad$ Population Aging and the Maintenance of Social Support Systems

F.T. Denton

B.G. Spencer

No. 10: The Changing Contexts of Family Care in Canada

C.J. Rosenthal 